\title{
Construction of Single Axis Automatic Solar Tracking System
}

\author{
Md. Khalid Iqbal ${ }^{1}$, Tanvir Islam ${ }^{2}$, M. Chowdhury ${ }^{1}$, Ahmed Imteaj $^{1}$ \\ ${ }^{1}$ Department of Computer Science \& Engineering, Chittagong University of \\ Engineering \& Technology, Chittagong, Bangladesh \\ ${ }^{2}$ Department of Electrical \& Electronic Engineering, Daffodil International \\ University, Dhaka, Bangladesh \\ [E-mail: khalidcuet@yahoo.com,tanvir263@yahoo.com,imtu_1992@yahoo.com]
}

\begin{abstract}
Solar power is the transformation of daylight into power, either straightforwardly utilizing photovoltaic $(P V)$, or in a roundabout way controlling concentrated sun powered force $(C S P)$. Concentrated sun powered force frameworks use lenses or mirrors and following frameworks to center a huge region of daylight into a little pillar. A feasible approach to maximize the efficiency of solar array systems is sun tracking. This paper demonstrates a novel method which will automatically track the sun's position and accordingly change the direction of the solar panel to get the maximum output from the solar cell with the help with IC LM339N, Sensor (LDR) and DC geared motor. This paper offers a dependable and reasonable strategy for adjusting a aligning a solar module with the sun keeping in mind the end goal to maximize its energy output.
\end{abstract}

Keywords: Solar power, tracking sun's position, maximizes output

\section{Introduction}

A worldwide temperature alteration is one of the real dangers for the survival of people and in addition endless species. Sunlight based force can be powerful in this respect which serves to abate/stop a dangerous atmospheric deviations. In this way, it can be an answer for the unnatural weather change emergency.

The issue of the worldwide temperature alteration is mounting step by step. The use of the rechargeable battery is expanding in the last few years because of electronic gadgets, for example, mp3 player, advanced mobile phone and tablet, and so forth. So the vitality asset is reducing and in addition humankind's presence is staying in risk. Fortunately, decades (or even hundreds of years) of exploration have prompted effective sun oriented board frameworks that make power without delivering a worldwide temperature alteration contamination [1]. A non-renewable vitality like sun based charger can enhance the condition on the grounds that it is utilizing completely free and clean vitality in the charging procedure. Solar energy is also frequently used for transportation signaling, e.g. light houses and in road traffic warning signals. The great benefit of solar energy is that it is sustainable, highly reliable and requires little maintenance [2].

The yield of sun powered cells relies on upon the force of daylight and the edge of frequency. That implies for getting most extreme productivity, the sun based boards must stay simply directly under the sun amid the entire day. Yet because of the turn of earth, the boards can't generally keep up their position.

At present, the greater parts of the sunlight based boards are stationary \& they are constantly confronted to stand out bearing; while the position of the sun continues changing 
in a day. Accordingly, the force of daylight falling on the sun based board isn't in most elevated amount which deceives the execution. Coordination of the sun oriented charger and the sunlight based following framework can be valuable for the enhancement of the execution.

Thus to get a constant output, an automated system is required which should be capable of rotating the solar panel constantly. 'The Solar Tracking System' is made as a prototype to solve the problem which is completely automated and it keeps the panel right under the sun where we get maximum output.

The main contributions of this paper are given below:

- Designing and constructing an automatic solar tracking system where the system aligns and orientates the position of solar panel according to light intensity falling on it. It is constructed for keeping the surface of the solar panel always perpendicular to the sun's position so that lights falling on the solar panel remain at maximum level.

- Integrating solar charger with the solar tracking system which increases the total efficiency of a solar system.

\section{Background and Related Works}

By and large, sun powered boards are stationary and don't take after the development of the sun. In [3] they proposed a sunlight based tracker framework which tracks the sun's development over the sky and tries to keep up the sun oriented board perpendicular to the sun's beam. It guarantees that the most extreme measure of daylight is episode on the board for the duration of the day till nighttime.

Photovoltaic is the field of engineering and exploration identified with the application of sun oriented cells as sun powered vitality [4] photovoltaic exhibits create a type of renewable power, especially helpful in circumstances where electrical force from the framework is occupied, for example, in remote territory power frameworks, Earth-circling satellites and space tests, remote radiotelephones and water pumping applications. Photovoltaic power is likewise progressively conveyed in matrix tied electrical frameworks.

Sun synchronous route is proficient by heading out inverse to planetary pivot, exploring with the sun, to remain constantly in daylight [6]. At suitable disposition and rate, the wanderers can keep up consistent introduction to sun powered radiation sufficient for supported operation.

The paper gives the design and implementation of a fuzzy logic computer controlled sun tracking system to enhance the power output of photo voltaic solar panels. The tracking system was driven by two permanent magnet DC motors provide motion of the panels in two axes. The paper describes the use of a microcontroller based design methodology of an automatic solar tracker. But sometimes its efficiency is not up to the mark.

The main purpose of this paper is to charge small electronic device by using the solar charging system and maximize the efficiency of the solar panel by creating solar tracking system.

\section{Methodology}

- East: Initiate the sensor

- During the day tracker function as the usual

- West: tracker function as usual

- At Evening and night tracker doesn't react. 
A sun oriented cell, now and then called a photovoltaic cell, is a gadget that changes over light vitality into electrical vitality. A solitary sun oriented cell makes a little measure of vitality (around .6 volts DC) so they are normally assembled together in a coordinated electrical board called a sun based board. Daylight is a to a degree diffuse type of vitality and just a share of the light caught by a sun powered cell is changed over into power.

Daylight is comprised of bundles of vitality called photons. At the point when the photons strike the semi-conductor layer (typically silicon) of a sunlight based cell, a part of the photons is retained by the material instead of ricocheting off it or experiencing the material. At the point when a photon is consumed, the vitality of that photon is exchanged to an electron in an iota of the cell bringing on the electron to escape from its typical position. This makes fundamentally, a gap in the molecule. This opening pulls in an alternate electron from a close-by particle now making yet an alternate entire, which thus filled again by an electron from an alternate molecule.

One of the problems with solar power is that the output of the solar panel is variable. These solar systems are designed to extract the maximum amount of power available from the solar panels and deposit it in the battery. These solar charge controllers also protect panels from discharging through the batteries after the sun goes down.

The solar panels used to capture and convert energy from the sun into electrons are offered in various volts gradations; a solar panel battery charger is available from 2 watt to 30 watt range.

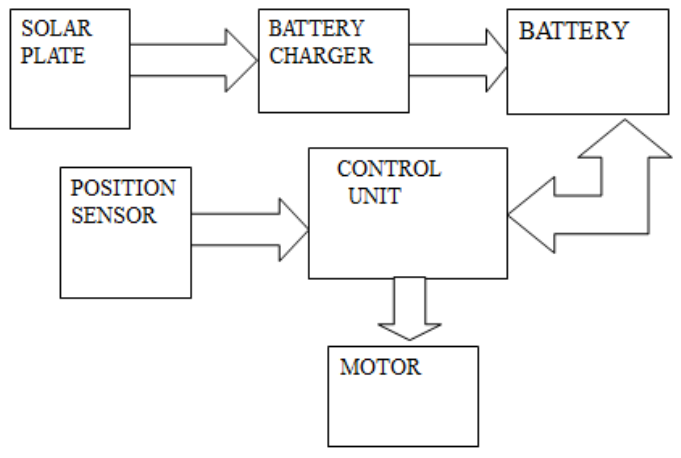

Figure 1. System Overview

Table 1. Voltage and Current Specification

\begin{tabular}{|l|c|}
\hline Discrete Components & Ratings \\
\hline Lead Acid Battery Voltage & 12 VDC \\
\hline Maximum Solar PV panel open circuit voltage & $18 \mathrm{VDC}$ \\
\hline Continuous charge/load current & $800 \mathrm{~mA}$ \\
\hline Maximum solar charge current (5 min) & $850 \mathrm{~mA}$ \\
\hline Voltage across terminals (PV to Battery) & $0.6 \mathrm{~V}$ \\
\hline Voltage across terminals (Battery to Load) & $0.3 \mathrm{~V}$ \\
\hline
\end{tabular}

A LDR (Light needy resistor), as its name proposes, offers safety because of the encompassing light. The resistance decreases as the intensity of incident light increases, and vice versa. In the absence of light, LDR exhibits a resistance of the order of mega-ohms, 
which decrease to few hundred ohms in the presence of light. It can act as a sensor, since a shifting voltage drop can be gotten as per the differing light. It is comprised of cadmium sulfide (Cds).An LDR has a zigzag cadmium sulfide track. It is a bilateral device, i.e., conducts in both directions in same fashion.

\subsection{Operation Principle}

Shows the circuit of the single axis solar tracking system the solar tracker comprises comparator IC LM339N, H-bridge motor driver IC L293D (IC2) and a few discrete components. Light-dependent resistors LDR1 through LDR2 are used as sensors to detect the panel's position relative to the sun. These provide the signal to motor driver IC 2 to move the solar panel in the sun's direction. LDR1 and LDR2 are fixed at the edges of the solar panel along the $\mathrm{X}$ axis, and connected to comparators A1 and A2, respectively. Presets VR1 and VR2 are set to get low comparator output at pins 2 and 1 of comparators A1 and A2, respectively, so as to stop motor M1 when the sun's rays are perpendicular to the solar panel. When LDR2 receives more light than LDR1, it offers lower resistance than LDR1, providing a high input to comparators $\mathrm{A} 1$ and $\mathrm{A} 2$ at pins 4 and 7, respectively. As a result, output pin 1 of comparator A2 goes high to rotate motor M1 in one direction say, anti-clockwise and turn the solar panel.

When LDR1 receives more light than LDR2, it offers lower resistance than LDR2, giving a low input to comparators $\mathrm{A} 1$ and $\mathrm{A} 2$ at pins 4 and 7 , respectively. As the voltage at pin 5 of comparator A1 is now higher than the voltage at its pin 4, its output pin 2 goes high. As a result, motor M1 rotates in the opposite direction (say, clock-wise) and the solar panel turns. Similarly, LDR3 and LDR4 track the sun along Y axis. Fig. 2 shows the logic diagram of the procedure.

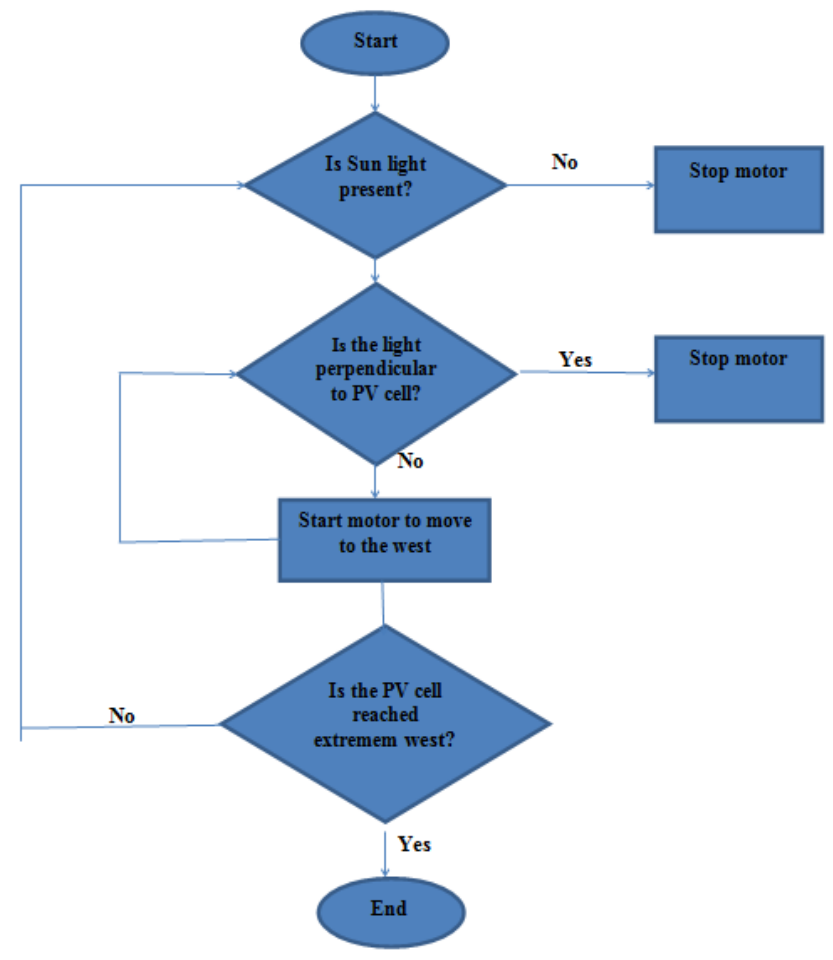

Figure 2. Logic Diagram 


\subsection{L293D Logic Table}

Let's consider a motor connected on left side output pins (pin 3, 6). For rotating the motor in clockwise direction the input pins have to be provided with Logic 1 and Logic 0.

$\operatorname{Pin} 2=\operatorname{Logic} 1$ and $\operatorname{Pin} 7=\operatorname{Logic} 0$

Pin $2=\operatorname{Logic} 0$ and Pin $7=\operatorname{Logic} 1$

Pin $2=\operatorname{Logic} 0$ and Pin $7=\operatorname{Logic} 0$

Pin $2=\operatorname{Logic} 1$ and Pin $7=\operatorname{Logic} 1$
Clockwise Direction

I Anticlockwise Direction

Idle [No rotation] [Hi- Impedance state]

Idle [No rotation]

In a very similar way the motor can also operate across input pin 15,10 for the motor on the right hand side.

\subsection{Equipments}

\begin{tabular}{|c|c|c|}
\hline Name & Model / Value & Quantity \\
\hline Integrated circuit ( IC) & LM339N & 1 \\
\hline Integrated circuit ( IC) & L293D & 2 \\
\hline Diode & $1 \mathrm{~N} 4148$ & 2 \\
\hline $\begin{array}{c}\text { Light Dependent } \\
\text { Resistors }\end{array}$ & & 1 \\
\hline Resistance & $10 \mathrm{~K}$ & 1 \\
\hline Resistance & $12 \mathrm{~K}$ & 1 \\
\hline Resistance & $22 \mathrm{~K}$ & 1 \\
\hline Resistance & $47 \mathrm{~K}$ & 1 \\
\hline Variable resistance & $47 \mathrm{~K}$ & 2 \\
\hline Variable resistance & $100 \mathrm{~K}$ & 1 \\
\hline Motor & $12 \mathrm{~V} 4$ RPM Geared Motor & 1 \\
\hline Project board & & \\
\hline Supply & $+12 \mathrm{~V}$ & 1 \\
\hline Circuit Board & & \\
\hline
\end{tabular}

\subsection{Working of Gear Motor}

The DC motor works over a fair range of voltage. The higher the input voltage more is the RPM (rotations per minute) of the motor. For example, if the motor works in the range of 6$12 \mathrm{~V}$, it will have the least RPM at $6 \mathrm{~V}$ and maximum at $12 \mathrm{~V}$ [5].

In terms of voltage, we can put the equation as:

Where,

$\mathrm{RPM}=\mathrm{K} 1 * \mathrm{~V}$,

$\mathrm{K} 1=$ Induced voltage constant

$\mathrm{V}=$ Applied voltage 
The working of the gears can be explained by the principle of conservation of angular momentum. The gear having smaller radius will cover more RPM than the one with larger radius. However, the larger gear will give more torque to the smaller gear than vice versa. The comparison of angular velocity between input gear (the one that transfers energy) to the output gear gives the gear ratio. When multiple gears are connected together, conservation of energy is also followed. The direction in which the other gear rotates is always the opposite of the gear adjacent to it.

In any DC motor, RPM and torque are inversely proportional. Hence the gear having more torque will provide a lesser RPM and converse. In a geared DC motor, the concept of pulse width modulation is applied. The equations detailing the working and torque transfer of gears are shown below:

$\mathrm{T}_{\text {in }} \mathrm{W}_{\text {in }}=\mathrm{T}_{\text {out }} \mathrm{W}_{\text {out }}$

Where,

$\mathrm{T}_{\mathrm{in}}=$ Input torque by the driver gear

$\mathrm{w}_{\mathrm{in}}=$ Angular speed of the driver gear

$\mathrm{T}_{\text {out }}=$ Output torque of the driver gear

$\mathrm{w}_{\text {out }}=$ Angular speed of the driver gear

In a geared DC motor, the gear connecting the motor and the gear head is quite small, hence it transfers more speed to the large teeth part of the gear head and makes it rotate. The larger part of the gear further turns the smaller duplex part. The small duplex port receives the torque, but not the speed of its predecessor, which it transfers to a larger part of other gear and so on. The third gear's duplex part has more teeth than others and hence it transfers more torque to the gear that is connected to the shaft [5].

\subsection{Circuit Diagram}

The circuit shows the single axis solar tracking system. The solar tracker comprises comparator IC LM339N, H-bridge motor driver IC L293D (IC2) \& few discrete components. Light-dependent resistors LDR1 through LDR2 are used as sensors to detect the panel's position relative to the sun.

These provide the signal to motor driver IC2 to move the solar panel in the sun's direction. LDR1 and LDR2 are fixed at the edges of the solar panel along the $\mathrm{X}$ axis, and connected to comparators A1 and A2, respectively. Presets VR1 and VR2 are set to get low comparator output at pins 2 and 1 of comparators A1 and A2, respectively, so as to stop motor $\mathrm{M}$ when the sun's rays are perpendicular to the solar panel.

When LDR2 receives more light than LDR1, it offers lower resistance than LDR1, providing a high input to comparators $\mathrm{A} 1$ and $\mathrm{A} 2$ at pins 4 and 7, respectively. As a result, output pin 1 of the comparator A2 goes high to rotate motor $\mathrm{M}$ in one direction (say, anticlockwise) and turn the solar panel.

When LDR1 receives more light than LDR2, it offers lower resistance than LDR2, giving a low input to comparators $\mathrm{A} 1$ and $\mathrm{A} 2$ at pins 4 and 7 , respectively. As the voltage at pin 5 of comparator A1 is now higher than the voltage at its pin 4, its output pin 2 goes high. As a result, motor $M$ rotates in the opposite direction (say, clockwise) and the solar panel turns.

Similarly, LDR3 and LDR4 track the sun along Y axis. 


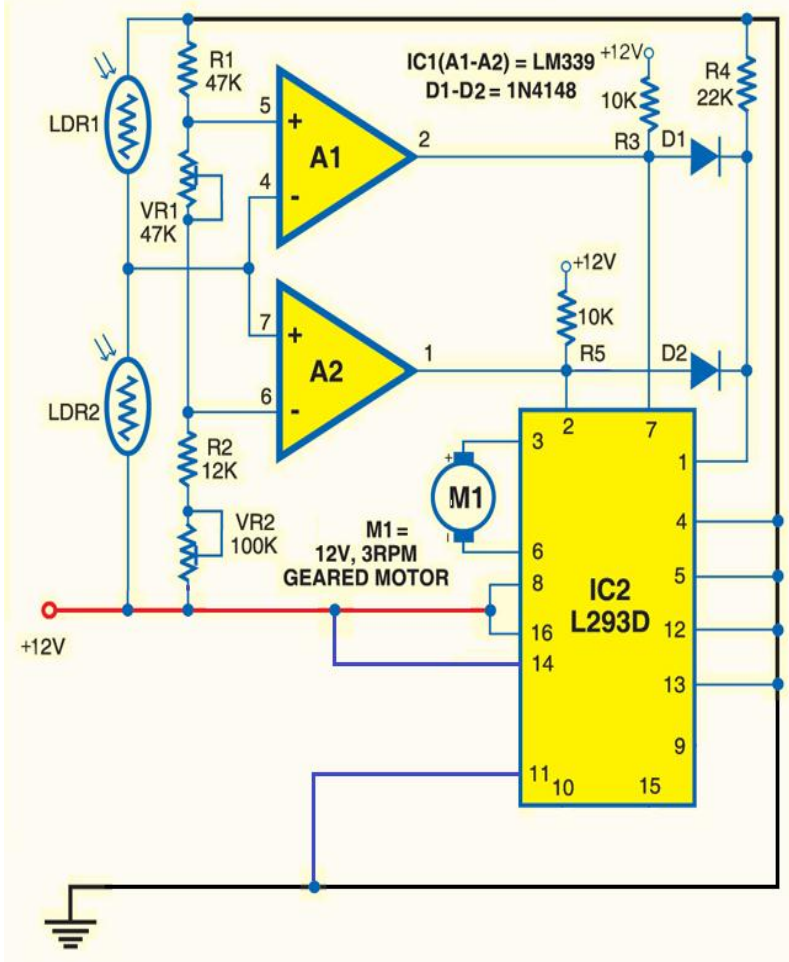

Figure 3. Circuit Diagram of Single Axis Solar Tracker

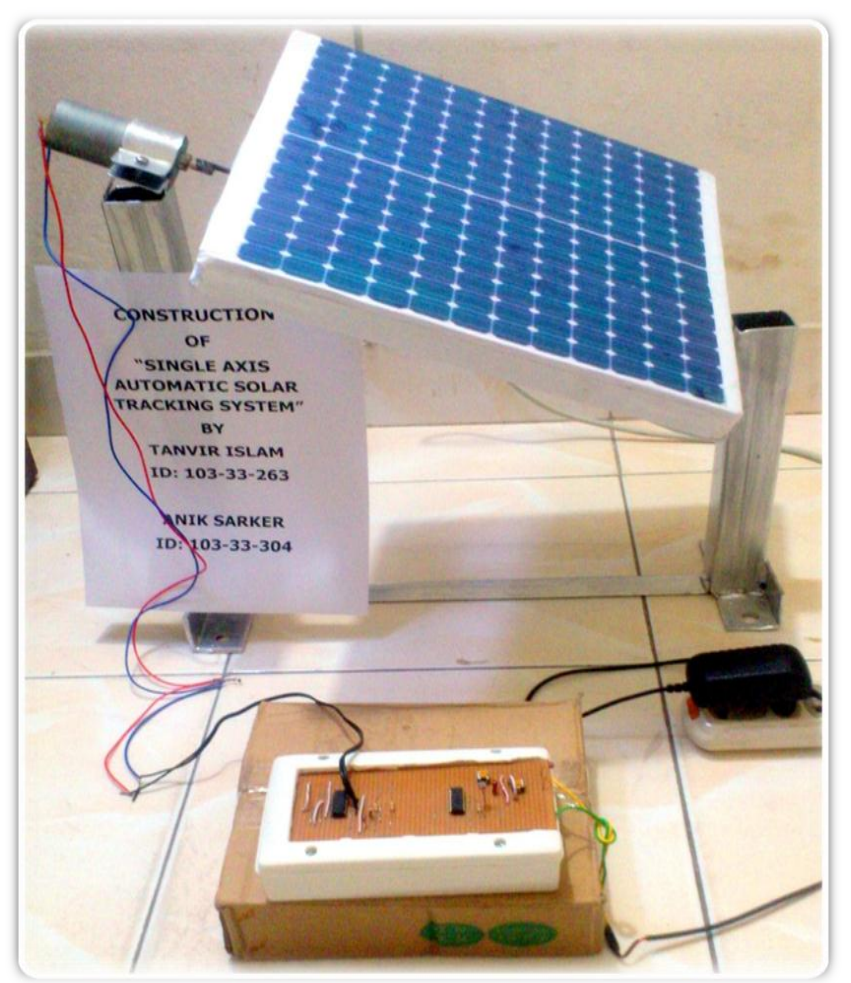

Figure 4. Proposed Assembly for the Single Axis Automatic Solar Tracker 


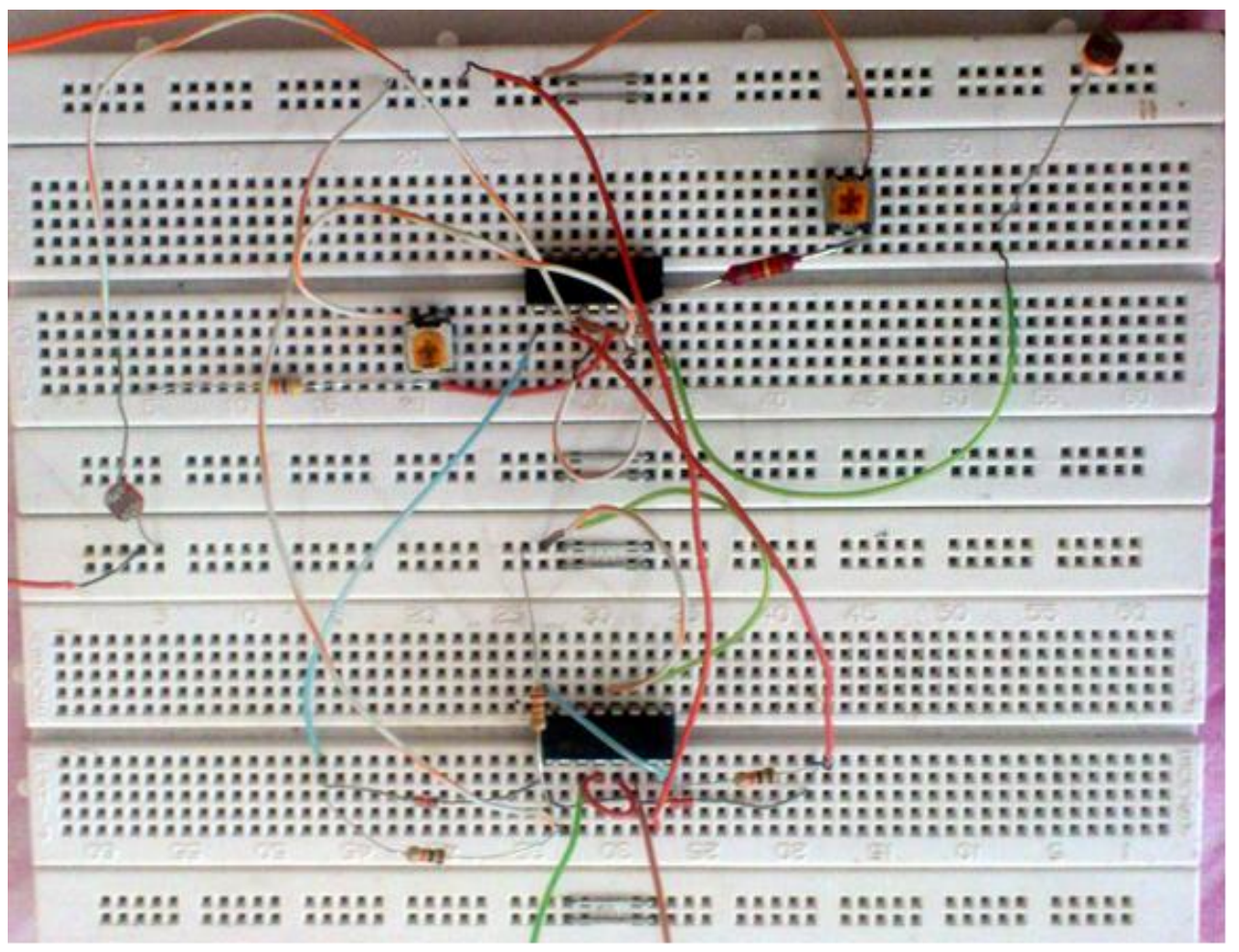

Figure 5. Circuit Diagram of the Single Axis Automatic Solar Tracker

\section{Experimental Results}

\subsection{Calculated Output}

Here we have used DC geared motor of 4 R.P.M, 12 Vdc, to rotate the solar panel from east to west and reverse direction.

The circuit takes $24 \mathrm{~mA}$ at $12 \mathrm{Vdc}$. So, the required Power $=24 \mathrm{~mA}^{*} 12 \mathrm{~V}=288 \mathrm{~mW} / \mathrm{sec}$.

For $6 \mathrm{sec}$., The required power $=288 * 6=1728 \mathrm{~mW}=1.8 \mathrm{~W}$.

In a day the panel (or we can say motor) moves east to west and back to east.

For 4 rotations the motor takes $1 \mathrm{~min} / 60 \mathrm{sec}$.

Therefore, for 1 rotation (360 degree) the motor takes $(60 / 4)=15 \mathrm{sec}$.

To rotate from east to west (180 degree) the motor takes $7.5 \mathrm{sec}$.

So, for 10 degree displacement it takes $(3000 \mathrm{~ms} * 10$ degree $) / 180$ degree $=167 \mathrm{msec}$.

In general, the moves from east to west, i.e. 180degree in 12 hours (6am to $6 \mathrm{pm}$ ) or 720 mins.

For 4 degree displacement, the sun takes $720 / 180=40$ mins.

So, in $2 \mathrm{hrs}$ the sun travels 30degree. To cover this 30degree displacement the panel takes $(67 * 3) \mathrm{msec}=201 \mathrm{msec}$.

\subsection{General Output}

\begin{tabular}{|l|l|l|l|}
\hline Time of day & $\begin{array}{l}\text { Open circuit } \\
\text { voltage(V) }\end{array}$ & $\begin{array}{l}\text { Closed } \\
\text { circuit } \\
\text { voltage(V) }\end{array}$ & $\begin{array}{l}\text { Current at fixed } \\
\text { angle 0 } \\
\text { degree(Amperes) }\end{array}$ \\
\hline 8.00 A.M & 19.07 & 15 & 0.59 \\
\hline
\end{tabular}




\begin{tabular}{|l|l|l|l|}
\hline 9.00 A.M & 19.08 & 15 & 0.71 \\
\hline 10.00 A.M & 18.74 & 15 & 0.65 \\
\hline 11.00 A.M & 18.66 & 15 & 0.64 \\
\hline 12.00 noon & 18.80 & 15 & 0.69 \\
\hline 1:00 P.M & 18.78 & 15 & 0.60 \\
\hline 2:00 P.M & 18.74 & 15 & 0.64 \\
\hline 3:00 P.M & 18.54 & 15 & 0.63 \\
\hline 4:00 P.M & 19.12 & 15 & 0.59 \\
\hline 5:00 P.M & 18.97 & 15 & 0.44 \\
\hline Total & & & 6.18 \\
\hline
\end{tabular}

\subsection{Designed Instrument's Output}

\begin{tabular}{|c|c|c|c|}
\hline Time of day & $\begin{array}{l}\text { Open circuit } \\
\text { voltage }(\mathrm{V})\end{array}$ & $\begin{array}{l}\text { Closed } \\
\text { circuit } \\
\text { voltage }(\mathrm{V})\end{array}$ & $\begin{array}{l}\text { Maximum current } \\
\text { at variable angle } \\
\text { (Amperes) }\end{array}$ \\
\hline 8.00 A.M & 19.07 & 15 & 0.75 \\
\hline 8.00 A.M & 19.08 & 15 & 0.73 \\
\hline 10.00 A.M & 18.74 & 15 & 0.71 \\
\hline 11.00 A.M & 18.66 & 15 & 0.70 \\
\hline 12.00 noon & 18.80 & 15 & 0.67 \\
\hline 1:00 P.M & 18.78 & 15 & 0.65 \\
\hline 2:00 P.M & 18.74 & 15 & 0.64 \\
\hline 3:00 P.M & 18.54 & 15 & 0.63 \\
\hline 4:00 P.M & 19.12 & 15 & 0.60 \\
\hline 5:00 P.M & 18.97 & 15 & 0.58 \\
\hline \multicolumn{3}{|c|}{ Total } & 6.66 \\
\hline
\end{tabular}

\subsection{Comparison of Two Outputs}

\begin{tabular}{|l|l|l|l|l|l|}
\hline & & & Rurent at fixed \\
Time of day & $\begin{array}{l}\text { Open Circuit } \\
\text { Voltage (V) } \\
\text { Angle 0 } \\
\text { Degree } \\
\text { (Amperes) }\end{array}$ & $\begin{array}{l}\text { Closed } \\
\text { Circuit } \\
\text { Voltage (V) }\end{array}$ & $\begin{array}{l}\text { Variable } \\
\text { Angle } \\
\text { (Degrees) for } \\
\text { Maximum } \\
\text { Current }\end{array}$ & $\begin{array}{l}\text { Maximum } \\
\text { Current } \\
\text { at Variable } \\
\text { Angle } \\
\text { (Amperes) }\end{array}$ \\
\hline 8.00 A.M & 19.07 & 15 & 0.59 & -30 & 0.75 \\
\hline
\end{tabular}




\begin{tabular}{|l|l|l|l|l|l|}
\hline 9.00 A.M & 19.08 & 15 & 0.71 & -15 & 0.73 \\
\hline 10.00 A.M & 18.74 & 15 & 0.65 & -15 & 0.71 \\
\hline 11.00 A.M & 18.66 & 15 & 0.64 & 0 & 0.70 \\
\hline 12.00 noon & 18.80 & 15 & 0.69 & 0 & 0.67 \\
\hline 1:00 P.M & 18.78 & 15 & 0.60 & 0 & 0.65 \\
\hline 2:00 P.M & 18.74 & 15 & 0.64 & 0 & 0.64 \\
\hline 3:00 P.M & 18.54 & 15 & 0.63 & 0 & 0.63 \\
\hline 4:00 P.M & 19.12 & 15 & 0.59 & +15 & 0.60 \\
\hline 5:00 P.M & 18.97 & 15 & 0.44 & +30 & 0.58 \\
\hline \multicolumn{1}{|c|}{ Total } & & 6.18 & & \multirow{2}{*}{6.66} \\
\cline { 3 - 5 } & & & &
\end{tabular}

\subsection{Comparison of Two Output Graph}

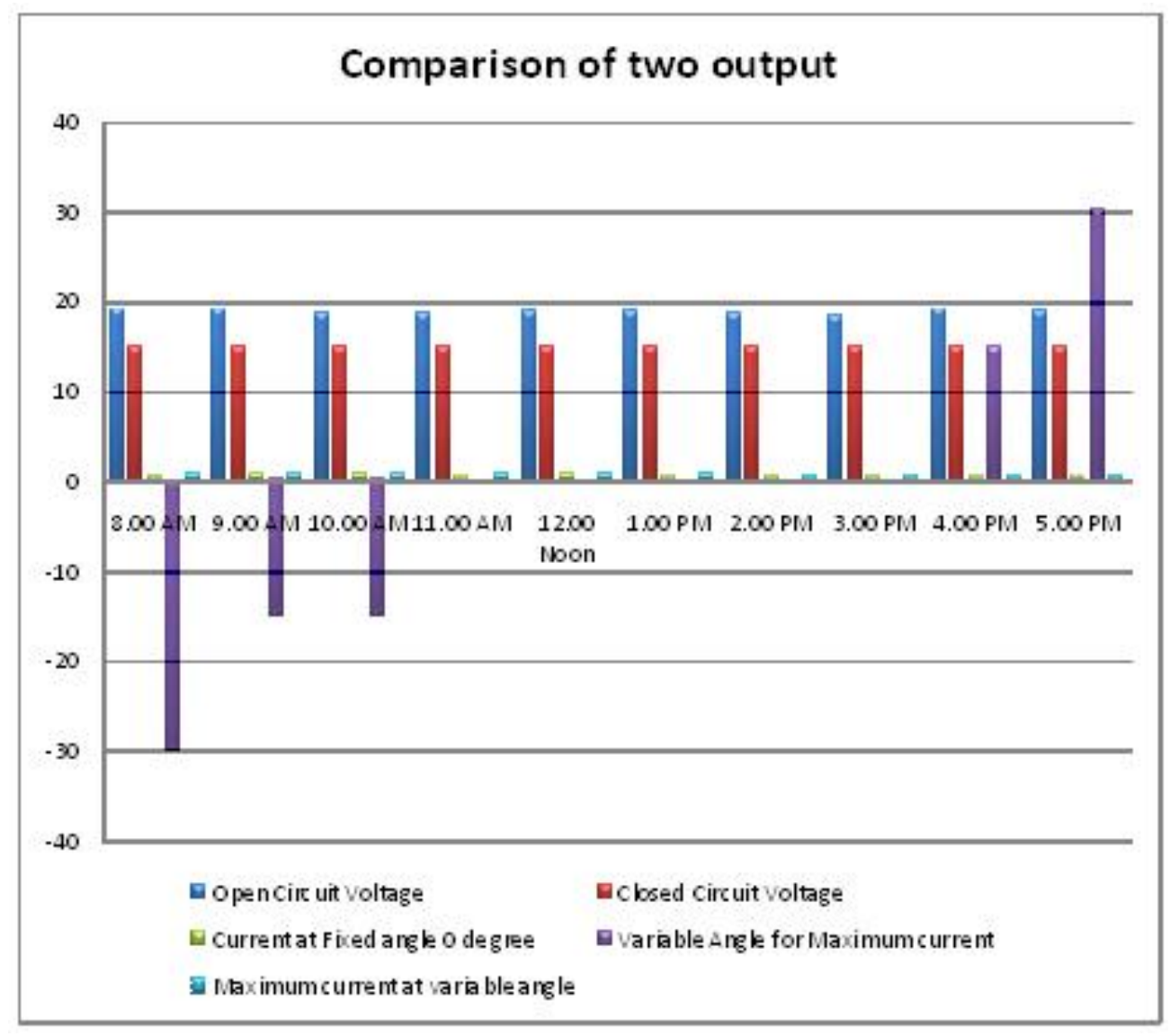

Figure 5. Comparison of Two Output Graph

\subsection{Calculating Efficiency}

Solar tracking is the easiest tactic to escalate overall efficiency of a solar power system for domestic or commercial users. We have calculated the efficiency as follows: Efficiency $=(\mathrm{A} / \mathrm{B}) * 100=7.767$

$\mathrm{A}=($ Maximum current at variable angle-current at fixed angle zero degree $)=(6.66-6.18)$ 
$\mathrm{B}=$ Current at fixed angle zero degree $=6.18$

\section{Conclusion and Future Recommendations}

A sun oriented tracker is intended to utilize the new standard of little sun powered cells to capacity as changing toward oneself light sensors; giving a variable sign of their relative point to the sun by recognizing their voltage yield. By using this method, the solar tracker can be triumphant in sustaining a solar array at a perpendicular angle to the sun. In future, rainfall sensors could be maneuvered to keep the system active during raining. Besides, in hereafter, when conventional energy may not be sufficient for us, there will be an entail of manipulating non-conventional energy source. By using this straightforward outline, it is feasible for a single person to build the gadget themselves.

\section{References}

[1] Advantages \& disadvantages of solar power, http://cleantechnica.com/2013/10/08/advantages-disadvantagessolar-power/

[2] Benefits of solar energy (Last date of access), http://www.greenoughsolarfarm.com.au/solar-energy/benefitssolar-energy

[3] T. Peterson, J. Rice and J. Valane, "Solar Tracker", ECE 476 (2005).

[4] A. K. Saxena and V. Dutta, "A versatile microprocessor- based controller for solar tracking", IEEE Proc., 1990, (1990) pp. $1105-1109$.

[5] N. Barsoun, "Implementation of a Prototype for a Traditional Solar Tracking System", The Third UKSim European Symposium on Computer Modeling and Simulation, (2009) pp. 23-30.

[6] C. Jaen, J. Pou, G. Capella, A. Arias, and M. Lamich, "On the use of sun trackers to improve maximum power point tracking controllers applied to photovoltaic systems", IEEE Conference on Compatibility and Power Electronics, (2009) pp. 67-72.

[7] Engineersgarage (Last date of access), http://www.engineersgarage.com/

[8] How a Gear Motor Works, http://www.doityourself.com/stry/how-a-gear-motor-works\#b

[9] Solar Energy, Renewable Energy and the Environment by Robert foster Alma cota. 
International Journal of $u-$ and e- Service, Science and Technology Vol.8, No.1 (2015) 